\title{
Anatomia foliar de mandioca em função do potencial para tolerância à diferentes condições ambientais ${ }^{1}$
}

\author{
Leaf anatomy of the cassava as related to potential for tolerance to different \\ environmental conditions
}

\author{
Márcia de Nazaré Oliveira Ribeiro ${ }^{2 *}$, Samuel Pereira de Carvalho ${ }^{3}$, Fabricio José Pereira ${ }^{4}$ e \\ Evaristo Mauro de Castro ${ }^{4}$
}

\begin{abstract}
Resumo - A mandioca é uma importante planta cultivada em regiões tropicais, possuindo grande variabilidade genética ainda pouco estudada. O objetivo desse trabalho foi analisar a anatomia foliar de treze genótipos, para avaliar o seu potencial para adaptação em diferentes condições ambientais. Foram coletadas folhas completamente expandidas de treze genótipos de mandioca sendo analisadas quanto às modificações quantitativas na estrutura interna sob microscopia óptica. O delineamento foi inteiramente casualizado com 12 repetições e 13 tratamentos, os dados foram submetidos à Anava e ao teste de Scott-Knott. Os diferentes genótipos apresentaram grande plasticidade anatômica para a maioria dos caracteres, sendo que as modificações mais importantes ocorreram na densidade e tamanho dos estômatos; espessura dos tecidos da epiderme da face abaxial, do parênquima paliçádico e esponjoso; no floema e no xilema. Os genótipos UFLA E, IAC 14 e UFLA J se caracterizam como potenciais para condições xéricas devido a alta densidade estomática, estômatos menores, maior espessura da epiderme adaxial, parênquima paliçádico e esponjoso, menor vulnerabilidade do xilema e maior espessura do floema, o que permitiria redução na transpiração e melhor aproveitamento de uma grande quantidade de radiação incidente. Os demais genótipos apresentam características mais mesófitas. Dessa forma, os genótipos de mandioca possuem plasticidade anatômica e podem apresentar potencial para a seleção de características desejáveis para diferentes condições ambientais.
\end{abstract}

Palavras-chave - Mandioca. Anatomia foliar. Plantas-efeito da seca. Euforbiácea.

\begin{abstract}
Cassava is an important plant, cultivated in tropical regions, possessing great genetic variability which has still hardly been studied. The objective of this work was to examine the leaf anatomy of thirteen genotypes to assess their potential for adaptation in different environmental conditions. Fully unfolded leaves were collected from thirteen cassava genotypes being analyzed for quantitative changes in internal structure using optical microscopy. The experimental design was completely randomized with 12 replications and 13 treatments, the data were submitted to ANOVA and the Scott-Knott test. The different genotypes displayed great anatomical plasticity for most characters, with the most important changes occurring in the density and size of the stomata, tissue thickness of the abaxial epidermis, of the palisade and spongy parenchyma, in the phloem and xylem. The UFLA E, IAC 14 and UFLA J genotypes displayed as possibilities for xeric conditions, due to a high stomatal density, smaller stomata, a thicker adaxial epidermis, thicker palisade and spongy parenchyma, lower vulnerability of the xylem and greater thickness of the phloem, which would allow reduction in transpiration and better use of a large amount of incident radiation. The other genotypes exhibit more mesophytic features. Thus, cassava genotypes have anatomical plasticity, and can display the potential for selection of desirable characteristics for different environmental conditions.
\end{abstract}

Key words - Cassava. Leaf anatomy. Drought effect-plants. Euphorbiaceae.

\footnotetext{
*Autor para correspondência

Recebido para publicação em 24/02/2010; aprovado em 17/11/2011

Parte da Tese de Doutorado do primeiro autor, apresentada ao Programa de Pós-Graduação em Agronomia/Fitotecnia, Universidade Federal de Lavras/ UFLA

${ }^{2}$ Bolsista de Pós-Doutoramento do CNPq, Empresa de Pesquisa Agropecuária de Minas Gerais (EPAMIG), Av. Visconde do Rio Preto, Campus CTAN/UFSJ, São João Del Rei-MG, Brasil, 36.301-360, marcia_162@ hotmail.com

${ }^{3}$ Departamento de Agricultura/UFLA, Caixa Postal 3.037, Lavras-MG, Brasil, 3.7200-000, samuelpc@ dag.ufla.br

${ }^{4}$ Departamento de Biologia/UFLA, Caixa Postal 3.037, Lavras-MG, Brasil, 37.200-000, fjprock@hotmail.com, emcastro@ufla.br
} 


\section{Introdução}

A mandioca (Manihot esculenta Crantz), família Euphorbiaceae, é uma planta tropical cultivada amplamente em várias regiões do mundo, sob condições de altas temperaturas e precipitação acima de $500 \mathrm{~mm}$, possuindo uma variabilidade genética ainda pouco conhecida (CERQUEIRA, 1992).

O centro de origem da mandioca está localizado na América Latina, sendo encontrada na forma nativa em uma grande área que abrange países como o Brasil, Peru, Venezuela, Guiana, Bolívia e Suriname, dificultando a indicação da região exata de origem (ALLEM, 1994). Em razão das regiões de origem das espécies de mandioca serem sujeitas à diferentes estresses, essas espécies podem exibir base genética para a tolerância à seca, altas temperaturas e mesmo à temperaturas mais amenas (NASSAR, 1979).

Várias características foram estudadas para avaliar a resposta das espécies vegetais ao déficit hídrico, destacando-se o potencial hídrico foliar (PIMENTEL; PEREZ, 2000), potencial osmótico e conteúdo relativo de água, temperatura foliar, condutância estomática e a transpiração (ANDRADE JÚNIOR et al., 2002; BASTOS et al., 2002; BEZERRA et al., 2003; LEITE et al., 2000). Trabalhos avaliando o potencial de plantas de mandioca para a adaptação a essas condições ambientais são escassos, sendo que para a maioria dos genótipos um ambiente com precipitação entre 1.000 e $1,500 \mathrm{~mm}$ é o mais adequado (NASSAR; ORTIZ, 2007). Contudo, existem muitos genótipos de mandioca (NASSAR; ORTIZ, 2007) e alguns genótipos podem demonstrar melhor tolerância à seca (CALATAYUD et al., 2002).

Os aspectos anatômicos da mandioca são ainda pouco estudados sendo que Nassar et al. (2008) destacam a importância do conhecimento dos aspectos anatômicos da espécie para os produtores, e relatam ainda variabilidade da estrutura do caule em função da poliploidia. Trabalhos com plantas do gênero demonstram que os tipos de frutos podem variar em relação às diferentes espécies quanto à esclerificação e deiscência(OLIVEIRA; OLIVEIRA, 2009). Modificações na anatomia foliar foram detectadas em diferentes cultivares de mandioca, promovendo diferenças na taxa fotossintética por modificar a relação área do mesofilo/área foliar, que pode modificar a difusão do $\mathrm{CO}_{2}$ (EL-SHARKAWY et al., 1989). Diferentes cultivares de mandioca demonstraram plasticidade para a anatomia foliar, exibindo diferenças nas características estomáticas, como a densidade, que podem demonstrar cultivares em potencial para a resistência à seca (CERQUEIRA, 1992).

As folhas de mandioca foram descritas por Ueno e Agarie (1997) como hipoestomáticas, com parênquima paliçádico e esponjoso definido, células da bainha do feixe desenvolvidas com cloroplastos distribuídos radialmente. As ceras cuticulares de mandioca são ricas em triterpenos e possuem alcanos e ácidos carboxílicos em menor quantidade, podendo variar entre os genótipos (ZINSOU et al., 2006). Apesar da ausência de estrutura Kranz típica, a fotossíntese na mandioca é considerada como $\mathrm{C}_{4}$ por alguns autores (COCK et al., 1987) ou como $\mathrm{C}_{3}$ por outros (UENO; AGARIE, 1997), ou mesmo como $\mathrm{C}_{3}-\mathrm{C}_{4}$ intermediárias, devendo ainda ser realizados outros estudos.

A anatomia vegetal pode indicar características que atribuem tolerância a diferentes condições ambientais para as plantas cultivadas, como tolerância à seca (BATISTA et al., 2010; GRISI et al., 2008) e características da radiação, tais como a qualidade e intensidade da radiação que incidem sobre as folhas das plantas (SANTIAGO et al., 2001) ou mesmo demais estresses como o alagamento (SOUZA et al., 2007; SOUZA et al., 2010) promovendo modificações na espessura do mesofilo, nos tecidos vasculares, na espessura da epiderme, na espessura da cutícula, na densidade e demais características estomáticas para a tolerância a essas condições.

Dessa forma, o presente trabalho teve como objetivo caracterizar a estrutura interna das folhas de 13 genótipos de mandioca, analisando essas características quanto ao potencial para a tolerância a ambientes mesofíticos e xerofíticos.

\section{Material e métodos}

O trabalho foi conduzido no campo experimental da Universidade Federal de Lavras (UFLA). Foram coletadas folhas de 13 genótipos de mandioca (Manihot esculenta Crantz), pertencentes ao Banco Ativo de Germoplasma (BAG) da UFLA, sendo as análises anatômicas conduzidas no Laboratório de Anatomia Vegetal da UFLA.

Foram coletadas as duas primeiras folhas completamente expandidas em três plantas por genótipo, sendo as folhas fixadas em F.A.A.70 (Formaldeído, ácido acético glacial e etanol $70 \%$ na proporção de 0,$5 ; 0,5 ; 9,0$ ) por 72 horas, sendo posteriormente armazenadas em etanol 70\% (JOHANSEN, 1940). Foram selecionados os genótipos: Baiana, Baianinha, Fibra, IAC 12, IAC 13, IAC 14, IAC 15, Mocotó, Ouro do Vale, UFLA E, UFLA G, UFLA H e UFLA J, os quais foram cultivados em condições de campo com adubação e correção do solo de acordo com as recomendações e irrigação diária até a capacidade de campo, proporcionando condições hídricas ideais para todos os genótipos estudados (CERQUEIRA, 1992; NASSAR; ORTIZ, 2007).

Foram realizados cortes paradérmicos na região central dos dois lobos basais de cada uma das folhas coletadas, utilizando-se lâmina de aço e cortes transversais da região 
mediana do lobo central de cada uma das folhas utilizandose um micrótomo de mesa modelo LPC. Os cortes foram clarificados com hipoclorito de sódio 50\% (comercial), lavados em água destilada por duas vezes durante 10 minutos, corados com solução de safranina $1 \%$ para os cortes paradérmicos ou solução safrablau (safranina $1 \%$ e azul de astra $0,1 \%$ na proporção de 7:3) para os cortes transversais, sendo posteriormente montados em lâmina e lamínula com água glicerinada (1:1), as lâminas foram seladas com resina de nitrocelulose.

As lâminas foram observadas e fotografadas em microscópio óptico modelo Olympus BX 60 acoplado à câmera digital Canon A630. As imagens foram analisadas em software para análise de imagens UTHSCSA Imagetool, com a medição de cinco campos por repetição para cada variável analisada. Foram medidas: $\mathrm{DP}=$ diâmetro polar dos estômatos; $\mathrm{DQ}$ = diâmetro equatorial dos estômatos; $\mathrm{NE}=$ número de estômatos; $\mathrm{NCE}=$ número de células epidérmicas; $\mathrm{EAD}=$ espessura da epiderme da face adaxial; $\mathrm{EAB}=$ espessura da epiderme da face abaxial; $\mathrm{PP}=$ espessura do parênquima paliçádico; $\mathrm{PE}=$ espessura do parênquima esponjoso; $\mathrm{CT}=$ espessura da cutícula; $\mathrm{FL}=$ espessura do floema; $\mathrm{NV}=$ número de vasos de metaxilema; $\mathrm{DX}=$ diâmetro dos elementos traqueais do xilema. Foram calculados a densidade estomática (DE - número de estômatos por unidade de área), o índice estomático (IE - percentual de estômatos em relação ao total de células epidérmicas por área) e a funcionalidade estomática (FUN - considerada como a relação diâmetro polar/diâmetro equatorial dos estômatos) segundo Castro et al. (2009) e o índice de vulnerabilidade de Carlquist para o xilema segundo Carlquist (1975) e Castro et al. (2009).

O delineamento foi inteiramente casualizado com 12 repetições e 13 tratamentos, e a parcela experimental foi constituída por três campos de cinco secções anatômicas por folha, sendo avaliadas quatro folhas de três plantas por tratamento. Foram realizadas análises de variância e teste de Scott-Knott a 5\% de significância, utilizando-se o software de análise estatística Sisvar (FERREIRA, 2000).

\section{Resultados e discussão}

As folhas de todos os genótipos exibem estrutura dorsiventral em secção transversal (FIG. 1), as diferenças de espessura das folhas são evidentes entre os genótipos, contudo, a estrutura básica se mantém em todos os genótipos. A cutícula está presente apenas na face adaxial, seguida de uma epiderme unisseriada na face adaxial, parênquima paliçádico formado por uma camada de células com poucos espaços intercelulares, parênquima esponjoso formado por cinco camadas de células aproximadamente isodiamédricas com espaços intercelulares abundantes, a epiderme da face abaxial é formada por uma camada de células mais espessas que a da face adaxial, com papilas evidentes e a presença de estômatos localizados nos espaços delimitados pelas papilas, formando um microambiente adequado à restrição da transpiração excessiva (FIG. 1). Essa descrição e padrão da estrutura foliar para os genótipos estão de acordo com a descrita para a espécie por Ueno e Agarie (1997).

Os genótipos demonstraram diferentes características para as secções paradérmicas. O DP exibiu uma grande variação, demonstrando que as folhas de mandioca possuem plasticidade para essa característica (TAB. 1). Observa-se que o genótipo IAC 15 foi o que apresentou os maiores valores para essa característica sendo que o genótipo UFLA G, que exibiu os menores valores.

O diâmetro polar dos estômatos está diretamente relacionada com o tamanho dessas estruturas (CASTRO et al., 2009), sendo que características ambientais são diretamente relacionadas com o DP, que pode aumentar em resposta à deficiência hídrica (BATISTA et al., 2010; GRISI et al., 2008). Dessa forma, os estômatos do genótipo IAC 15 parecem ser maiores que os dos demais genótipos, e os estômatos maiores podem ser associados com uma menor densidade estomática (TAB. 1), que pode indicar uma melhor adaptação desse genótipo às condições de uma alta disponibilidade de água, e menor radiação (BOEGER; WISNIEWSKI, 2003). Contudo, o índice estomático pode variar diferentemente da densidade estomática, sendo que genótipos com pequenos estômatos e baixa densidade estomática como o IAC 13 e UFLA H podem apresentar índices estomáticos relativamente altos devido ao maior tamanho das células epidérmicas regulares (TAB. 1).

A redução da transpiração pode ser associada com uma maior funcionalidade estomática, pois os estômatos se tornam mais elípticos (BATISTA et al., 2010; CASTRO et al., 2009; SOUZA et al., 2010), a redução da transpiração pode ainda ser associada com uma maior DE, que frequentemente é observada em condições de maior quantidade de radiação e de menor disponibilidade de água (BOEGER; WISNIEWSKI, 2003; CASTRO et al., 2009; SANTIAGO et al., 2001; SOUZA et al., 2007).

Dessa forma, entre as variedades com maiores valores para a FUN e DE destacam-se os genótipos UFLA E, IAC 14 e UFLA J, sendo que as maiores médias aparecem no genótipo UFLA E (TAB. 1), com valores superiores às menores médias (obtidas nos genótipos Baiana, UFLA G e Mocotó) para a FUN, demonstrando que esse genótipo apresenta os estômatos mais funcionais, e, associados com uma maior DE, sendo superior ao grupo formado pelos genótipos Baiana, UFLA H, IAC 15, IAC 13 e Baianinha, que, claramente constituem um grupo que 
Figura 1 - Secções transversais das folhas de mandioca de diferentes genótipos
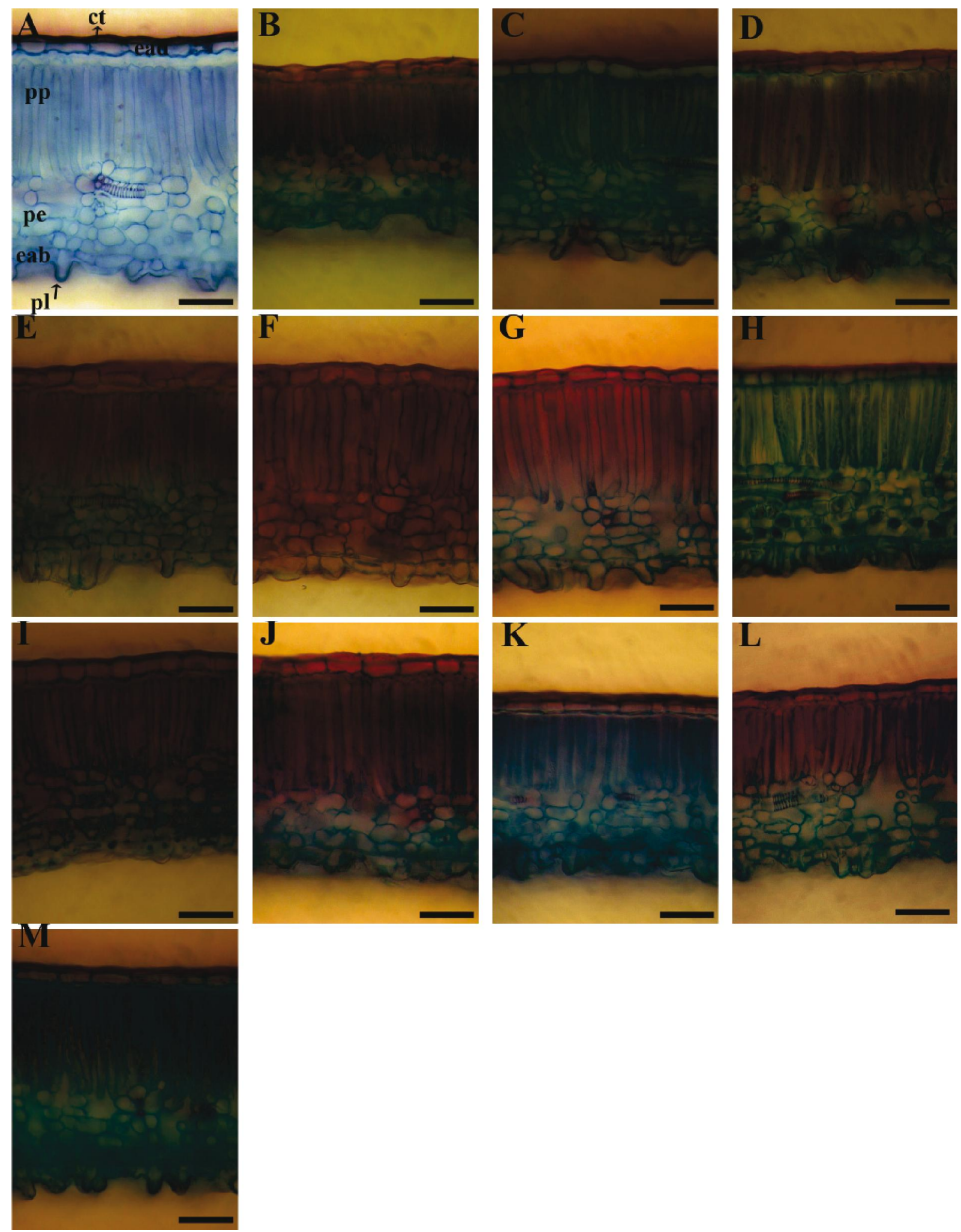

$\mathrm{ct}=$ cutícula, ead = epiderme da face adaxial, eab = epiderme da face abaxial, $\mathrm{pp}=$ parênquima paliçádico, pe = parênquima esponjoso, $\mathrm{pl}=$ papila . A = Baiana, B = Baianinha, C = Fibra, D = IAC 12, E = IAC 13, F = IAC 14, G = IAC 15, H = Mocotó, I = Ouro do Vale, J = UFLA E, K = UFLA G, L = UFLA $\mathrm{H}, \mathrm{M}=$ UFLA J. Barras $=50 \mu \mathrm{m}$ 
Tabela 1 - Características das secções paradérmicas da epiderme foliar dos genótipos de mandioca

\begin{tabular}{lccccc}
\hline \multicolumn{1}{c}{ Genótipos } & DP $(\mu \mathrm{m})$ & DQ $(\mu \mathrm{m})$ & FUN & DE & IE $(\%)$ \\
\hline Baiana & $43,61 \mathrm{c}$ & $27,94 \mathrm{a}$ & $1,56 \mathrm{~d}$ & $100,22 \mathrm{~d}$ & $09,65 \mathrm{~b}$ \\
Baianinha & $43,90 \mathrm{c}$ & $26,11 \mathrm{a}$ & $1,69 \mathrm{c}$ & $149,75 \mathrm{~b}$ & $12,83 \mathrm{~b}$ \\
Fibra & $38,48 \mathrm{~d}$ & $22,11 \mathrm{~b}$ & $1,74 \mathrm{c}$ & $132,06 \mathrm{c}$ & $10,27 \mathrm{~b}$ \\
IAC 12 & $45,18 \mathrm{~b}$ & $25,35 \mathrm{a}$ & $1,78 \mathrm{c}$ & $106,12 \mathrm{~d}$ & $08,38 \mathrm{c}$ \\
IAC 13 & $40,56 \mathrm{~d}$ & $23,38 \mathrm{~b}$ & $1,75 \mathrm{c}$ & $113,19 \mathrm{~d}$ & $09,37 \mathrm{~b}$ \\
IAC 14 & $45,33 \mathrm{~b}$ & $24,26 \mathrm{~b}$ & $1,87 \mathrm{~b}$ & $102,58 \mathrm{~d}$ & $09,04 \mathrm{c}$ \\
IAC 15 & $48,06 \mathrm{a}$ & $28,20 \mathrm{a}$ & $1,71 \mathrm{c}$ & $117,91 \mathrm{~d}$ & $10,44 \mathrm{~b}$ \\
Mocotó & $41,36 \mathrm{~d}$ & $27,30 \mathrm{a}$ & $1,52 \mathrm{~d}$ & $146,21 \mathrm{~b}$ & $11,55 \mathrm{a}$ \\
Ouro do Vale & $40,55 \mathrm{~d}$ & $23,10 \mathrm{~b}$ & $1,75 \mathrm{c}$ & $176,87 \mathrm{a}$ & $10,53 \mathrm{~b}$ \\
UFLA E & $42,82 \mathrm{c}$ & $20,40 \mathrm{~b}$ & $2,12 \mathrm{a}$ & $146,21 \mathrm{~b}$ & $11,93 \mathrm{a}$ \\
UFLA G & $35,32 \mathrm{e}$ & $22,71 \mathrm{~b}$ & $1,56 \mathrm{~d}$ & $187,18 \mathrm{a}$ & $12,47 \mathrm{a}$ \\
UFLA H & $39,09 \mathrm{~d}$ & $23,54 \mathrm{~b}$ & $1,66 \mathrm{c}$ & $101,40 \mathrm{~d}$ & $08,03 \mathrm{c}$ \\
UFLA J & $42,72 \mathrm{c}$ & $23,03 \mathrm{~b}$ & $1,86 \mathrm{~b}$ & $134,42 \mathrm{c}$ & $11,29 \mathrm{a}$ \\
Desvio padrão & $\pm 3,68$ & $\pm 2,81$ & $\pm 0,20$ & $\pm 28,94$ & $\pm 1,66$ \\
\hline DP & & &
\end{tabular}

$\mathrm{DP}=$ diâmetro polar dos estômatos; $\mathrm{DQ}=$ diâmetro equatorial dos estômatos; $\mathrm{DE}=$ densidade estomática (estômatos por mm²); FUN = Funcionalidade estomática; IE = índice estomático. Todos os valores são expressos como a média \pm desvio padrão. As médias seguidas de mesma letra na coluna não diferem entre si pelo teste de Scott-Knott para $\mathrm{P}<0,05$

necessita maior disponibilidade de água. Esses genótipos podem ser relacionados com as descrições na literatura da necessidade de precipitações entre 1.000 e $1.500 \mathrm{~mm}$ anuais para que não ocorram restrições no crescimento das plantas de mandioca (CERQUEIRA, 1992; NASSIR; ORTIZ, 2007). Dessa forma, o genótipo UFLA E pode ser reconhecido como o que possui características xerofíticas para os estômatos, sendo mais adaptado às condições de baixa disponibilidade de água.

As características xeromorfas da mandioca podem ter, em parte, uma base genética devido a origem dessa espécie em regiões quentes e seca (ALLEM, 1994). Esses resultados estão de acordo com Calatayud et al. (2002) que relatam que alguns genótipos de mandioca podem tolerar muitos meses de baixa disponibilidade hídrica. As maiores DE e FUN podem conferir ao genótipo UFLA E uma alta adaptabilidade a ambientes xéricos, sendo essas características frequentemente associadas com esse tipo de ambiente (CASTRO et al., 2009; GRISI et al., 2008). Segundo Cerqueira (1992), essa espécie demonstrou plasticidade na DE em condições de deficiência hídrica, sendo que o nível de plasticidade foi diferente para as diferentes cultivares. Dessa forma, uma maior DE pode permitir uma abertura em um espaço de tempo menor, permitindo uma captação adequada de $\mathrm{CO}_{2}$ e reduzindo o tempo em que esses estômatos ficam abertos, reduzindo, consequentemente a transpiração, permitindo uma melhor adaptação do genótipo UFLA $\mathrm{E}$ às condições de pouca disponibilidade de água.
Dentro dessas condições, os genótipos com características mais mesofíticas como definidas por Boeger e Wisniewski (2003) e Castro et al. (2009) (Baiana, UFLA H, UFLA G, Fibra, IAC 15, IAC 13, IAC 12, Baianinha, UFLA J e Ouro do Vale) com especial referência para o genótipo Mocotó, que possui uma alta densidade estomática com estômatos pouco funcionais (TAB. 1) que podem gerar uma excessiva transpiração para esse genótipo, dificultando a sua adaptação às condições mais secas. Esses dados corroboram as observações de Cerqueira (1992) que relata um aumento na densidade estomática nas folhas de genótipos de mandioca quando submetidos às condições de seca e enfatiza a importância dessa característica para a tolerância à seca na espécie.

Os estômatos em secção paradérmica são classificados como paracíticos em todos os genótipos estudados, e são localizados em depressões da epiderme, características de plantas xeromorfas (CASTRO et al., 2009). A presença dos estômatos em depressões é acentuadamente mais evidente nos genótipos UFLA E, IAC 14, UFLA J e Ouro do Vale, esse fato corrobora a maior xeromorfia das folhas do genótipo UFLAE em especial, além dos IAC 14 e UFLA J, podendo ainda ser favorável para o genótipo Ouro do Vale. Essa característica é interessante, contribuindo para a redução da transpiração nesses genótipos, diminuindo a ação de ventos, que podem ser diretamente relacionados com a transpiração por remover o vapor de água da camada limítrofe nas folhas, aumentando o déficit de pressão de 
vapor, promovendo um aumento na transpiração (CASTRO et al., 2009; STRECK, 2003). Segundo El-Sharkawy et al. (1989) a fotossíntese nas plantas de mandioca é reduzida quando a diferença de pressão de vapor entre a folha e o ar excede o valor de 1,5 KPa, estando esta redução intimamente relacionada com o fechamento estomático e subsequente redução na condutância foliar. Dessa forma, o genótipo UFLA E se destaca com características estomáticas para reduzir a transpiração, sendo o genótipo mais indicado para o cultivo em condições xéricas, podendo ainda, se destacar os genótipos IAC 14 e UFLA J.

O genótipo UFLA E se destaca também com adaptações para reduzir a perda de água, com a EAD sendo superior em espessura, em relação ao grupo formado pelos genótipos com características mesomórficas (TAB. 2), esse padrão se repete nos genótipos IAC 14 e UFLA J, que exibiram características xerofíticas em secção paradérmica (TAB. 1 e 2). A espessura da EAD pode estar relacionada com as condições de intensidade de radiação ou das condições hídricas (CASTRO et al., 2009; SOUZA et al., 2007), atenuando a radiação incidente e reduzindo a taxa transpiratória. Dessa forma, os genótipos UFLA E, IAC 14 e UFLA J, em associação com as características estomáticas (TAB. 1) podem ser mais tolerantes à seca e alta intensidade luminosa, podendo ser indicados para tais condições.

$\mathrm{A} E A B$ pode ser menos responsiva às variações ambientais em relação à $\mathrm{EAD}$, devido à radiação ser diretamente incidente sobre a epiderme da face adaxial (CASTRO et al., 2009) e a transpiração ocorrer principalmente pela epiderme da face abaxial (STRECK, 2003). A EAB pode não se modificar sob diferentes condições hídricas (BATISTA et al. 2010; GRISI et $a l .$, 2008) dessa forma, como as plantas dos diferentes genótipos estavam em condições semelhantes, não ocorreram diferenças na $\mathrm{EAB}(\mathrm{Fc}=0,985 ; \mathrm{P}=0,4755)$.

$\mathrm{O}$ genótipo com as maiores médias para o PP foi o IAC 12, com valores superiores que o grupo formado pelos genótipos de menor PP (genótipos UFLA H, UFLA G, Fibra, Baianinha e Ouro do Vale). Um segundo grupo, formado pelos genótipos: Baiana, UFLA E, IAC 15, IAC 13, Mocotó, IAC 14 e UFLA J demonstraram valores intermediários para a espessura do parênquima paliçádico (TAB. 2). Esses valores são associados com os valores de PE, que exibiu dois grupos, o que possui menores valores de PE, formado pelos genótipos UFLA G e Baianinha que demonstrou valores menores que os demais genótipos (TAB. 2).

Diferentes genótipos de café demonstram diferenças no potencial para a tolerância ao estresse hídrico quanto às espessuras do PP e PE (BATISTA et al., 2010), sendo que o PP está diretamente relacionado com a utilização da radiação na fotossíntese (CASTRO et al., 2009; SOUZA et al., 2010), e o PE está diretamente relacionado com a fotossíntese pela captação do $\mathrm{CO}_{2}$ (CASTRO et al., 2009). Dessa forma, os maiores valores para o PP e PE podem

Tabela 2 - Características dos tecidos foliares de diferentes genótipos de mandioca em secção transversal

\begin{tabular}{lccccc}
\hline \multicolumn{1}{c}{ Genótipos } & EAD $(\mu \mathrm{m})$ & PP $(\mu \mathrm{m})$ & PE $(\mu \mathrm{m})$ & IVC & FL $(\mu \mathrm{m})$ \\
\hline Baiana & $14,35 \mathrm{~b}$ & $119,22 \mathrm{~b}$ & $73,88 \mathrm{a}$ & $0,51 \mathrm{~d}$ & $122,03 \mathrm{a}$ \\
Baianinha & $11,86 \mathrm{~b}$ & $091,55 \mathrm{c}$ & $54,42 \mathrm{~b}$ & $1,03 \mathrm{a}$ & $116,64 \mathrm{a}$ \\
Fibra & $18,26 \mathrm{a}$ & $092,82 \mathrm{c}$ & $73,62 \mathrm{a}$ & $1,07 \mathrm{a}$ & $102,91 \mathrm{~b}$ \\
IAC 12 & $15,93 \mathrm{a}$ & $139,86 \mathrm{a}$ & $76,72 \mathrm{a}$ & $0,83 \mathrm{~b}$ & $114,80 \mathrm{a}$ \\
IAC 13 & $14,99 \mathrm{a}$ & $106,41 \mathrm{~b}$ & $64,39 \mathrm{a}$ & $0,64 \mathrm{~d}$ & $121,68 \mathrm{a}$ \\
IAC 14 & $15,39 \mathrm{a}$ & $120,72 \mathrm{~b}$ & $70,08 \mathrm{a}$ & $0,77 \mathrm{c}$ & $103,00 \mathrm{~b}$ \\
IAC 15 & $14,17 \mathrm{~b}$ & $113,78 \mathrm{~b}$ & $66,78 \mathrm{a}$ & $0,62 \mathrm{~d}$ & $116,88 \mathrm{a}$ \\
Mocotó & $14,32 \mathrm{~b}$ & $116,01 \mathrm{~b}$ & $70,65 \mathrm{a}$ & $0,75 \mathrm{c}$ & $107,92 \mathrm{~b}$ \\
Ouro do vale & $13,39 \mathrm{~b}$ & $094,80 \mathrm{c}$ & $64,72 \mathrm{a}$ & $0,85 \mathrm{~b}$ & $107,67 \mathrm{~b}$ \\
UFLA E & $16,27 \mathrm{a}$ & $112,96 \mathrm{~b}$ & $66,40 \mathrm{a}$ & $0,83 \mathrm{~b}$ & $120,21 \mathrm{a}$ \\
UFLA G & $13,30 \mathrm{~b}$ & $086,02 \mathrm{c}$ & $52,78 \mathrm{~b}$ & $1,06 \mathrm{a}$ & $092,99 \mathrm{~b}$ \\
UFLA H & $12,49 \mathrm{~b}$ & $090,35 \mathrm{c}$ & $70,52 \mathrm{a}$ & $0,86 \mathrm{~b}$ & $113,14 \mathrm{a}$ \\
UFLA J & $14,95 \mathrm{a}$ & $116,26 \mathrm{~b}$ & $81,58 \mathrm{a}$ & $0,85 \mathrm{~b}$ & $112,11 \mathrm{a}$ \\
Desvio padrão & $\pm 2,44$ & $\pm 17,92$ & $\pm 11,33$ & $\pm 0,19$ & $\pm 13,21$ \\
\hline
\end{tabular}

$\mathrm{EAD}=$ espessura da epiderme da face adaxial, $\mathrm{PP}=$ espessura do parênquima paliçádico, $\mathrm{PE}=$ espessura do parênquima esponjoso, IVC $=$ índice de vulnerabilidade de Carlquist, $\mathrm{FL}=$ espessura do floema. Todos os valores representam a média \pm desvio padrão da média. As médias seguidas de mesma letra na coluna não diferem entre si pelo teste de Scott-Knott para $(\mathrm{P}<0,05)$ 
conferir uma maior capacidade fotossintética aos genótipos que as exibem, sendo um fator favorável em condições de alta radiação incidente.

Em condições de alta radiação, ocorre uma maior espessura total das folhas, relacionada com o índice de esclerofilia (BOEGER; WISNIEWSKI, 2003) e com folhas de sol (CASTRO et al., 2009), sendo que o aumento em espessura das folhas pode promover uma maior capacidade fotossintética por promover uma maior quantidade de espaços intercelulares e espaço para alocação dos cloroplastos, aumentando a fotossíntese potencial (OGUCHI et al., 2003). A plasticidade das folhas de mandioca para aumentar o espaço interno de difusão de $\mathrm{CO}_{2}$ está de acordo com os resultados de ElSharkawy et al. (1989). Dessa forma, os maiores valores para a PP e PE podem ser relacionados diretamente com a fotossíntese e com a esclerofilia das folhas, que, dessa forma, podem ser adaptadas às maiores condições de radiação e de deficiência hídrica, dando destaque para os genótipos UFLA E, IAC 14 e UFLA J que, associados com as características estomáticas, podem ser mais eficientes para reduzir a transpiração e para aproveitar a radiação incidente.

A cutícula está diretamente relacionada com a redução da transpiração excessiva (CASTRO et al., 2009). Os diferentes genótipos de mandioca estudados nesse experimento não demonstraram diferenças endógenas $(\mathrm{Fc}=0,839 ; \mathrm{P}=0,6108)$. A pouca variação na $\mathrm{CT}$ em plantas de mandioca foi observada também por Zinsou et al. (2006), em resposta à infecção por patógenos. Contudo, se as plantas forem submetidas a condições de estresse hídrico e/ou radiação intensa, as diferenças na espessura da cutícula podem se tornar mais evidentes e os genótipos potencialmente mais xeromorfos podem demonstrar um espessamento na CT como demonstrado em diferentes espécies (BATISTA et al., 2010; SOUZA et al., 2010).

O IVC está diretamente relacionado com uma maior eficiência do sistema vascular das plantas podendo ser utilizado para inferir sobre a probabilidade de embolias no xilema, sendo diretamente relacionado com o número e diâmetro dos vasos de metaxilema (CARLQUIST, 1975; CASTRO et al., 2009; HACKE; SPERRY, 2001; SOUZA et al., 2009). O IVC pode variar de acordo com as condições ambientais, como a seca e o alagamento, sendo que a sua redução está relacionada com melhores condições do xilema para a condutividade hidráulica (CASTRO et al., 2009; PEREIRA et al., 2008).

Os genótipos que demonstraram algumas características xerófitas (UFLA E, IAC 14 e UFLA J) apresentaram valores menores para o IVC que o grupo de genótipos com as maiores médias (UFLA G, Fibra e Baianinha), sendo que os valores para o grupo xerofítico foram menores que as maiores médias (TAB. 2). Esses dados corroboram uma melhor condição dos genótipos UFLA E, IAC 14 e UFLA J para ambientes xerofíticos, que frequentemente pode levar à embolia no xilema (HACKE; SPERRY, 2001), e, associados com as demais características permitem a esses genótipos uma melhor adaptabilidade a essas condições. Contudo, os genótipos com os maiores valores de IVC podem requerer ambientes com grande disponibilidade de água, pois, dessa forma, o risco de embolias ou problemas de condutividade hidráulica podem ser reduzidos.

O FL foi diferente para os diferentes genótipos (TAB. 2), formando dois grupos, com os maiores valores sendo maiores que os menores valores. O floema está diretamente relacionado com a translocação de fotosintatos das folhas para os órgãos dreno (CASTRO et al., 2009). Dessa forma, os genótipos com os maiores valores para essa característica demonstram um maior potencial para translocação de fotoassimilados, podendo promover um maior desenvolvimento das raízes, produto de principal interesse para essa espécie. Destacam-se, nesse aspecto, os genótipos UFLA E e UFLA J para os ambientes xerofíticos, e, os genótipos Baiana, UFLA H, IAC 15, IAC 13, IAC 12 e Baianinha para os ambientes mesofíticos (TAB. 2), confirmando o potencial genético para a aclimatização em diferentes condições como observado por Nassar (1979) e Nassar e Ortiz (2007).

\section{Conclusões}

1. A estrutura interna dos 13 genótipos de mandioca estudados exibe diferenças que podem se relacionar com a adaptabilidade desses genótipos aos diferentes ambientes;

2. Os genótipos UFLA E, IAC 14 e UFLA J apresentam características mais xerofíticas em relação aos demais genótipos, sendo potencialmente mais adequadas a ambientes com pouca água e muita radiação;

3. Os genótipos Baiana, UFLA H, UFLA G, Fibra, IAC 15, IAC 13, Mocotó, Baianinha e Ouro do Vale apresentam características mais mesofíticas, sendo potencialmente mais adequados para regiões de boa disponibilidade de água.

\section{Referências}

ALLEM, A. C. The origin of Manihot esculenta Crantz (Euphorbiaceae). Genetics Resources and Crop Evolution, v. 41, n. 03, p. 133-150, 1994.

ANDRADE JÚNIOR, A. S. et al. Níveis de irrigação na cultura do feijão caupi. Revista Brasileira de Engenharia Agrícola e Ambiental, v. 06, n. 01, p. 17-20, 2002. 
BASTOS, E. A. et al. Parâmetros de crescimento do feijão caupi sob diferentes regimes hídricos. Engenharia Agrícola, v. 22, n. 01, p. 43-50, 2002.

BATISTA, L. A. et al. Anatomia foliar e potencial hídrico na tolerância de cultivares de café ao estresse hídrico. Revista Ciência Agronômica, v. 41, n. 03, p. 475-481, 2010.

BEZERRA, F. M. L. et al. Feijão caupi e déficit hídrico em suas fases fenológicas. Revista Ciência Agronômica, v. 34, n. 01, p. 13-18, 2003.

BOEGER,M.R.T.; WISNIEWSKI,C.Comparação da morfologia foliar de espécies arbóreas de três estádios sucessionais distintos de floresta ombrófila densa (Floresta Atlântica) no Sul do Brasil. Revista Brasileira de Botânica, v. 26, n. 01, p. 61-72, 2003.

CARLQUIST, S. Ecological strategies of xylem evolution. Berkeley: University of California Press, 1975. 259 p.

CASTRO, E. M.; PEREIRA, F. J.; PAIVA, R. Histologia Vegetal: estrutura e função dos órgãos vegetativos. Lavras: UFLA, 2009. 234 p.

CALATAYUD, P. A. et al. Wild Manihot species do not process $\mathrm{C}_{4}$ photosynthesis. Annals of Botany, v. 89, p. 125-127, 2002.

CERQUEIRA, Y. M. Efeito da deficiência de água na anatomia foliar de cultivares de mandioca Manihot esculenta Crantz. Idensidade estomática. Sitientibus, n. 10, p. 103-115, 1992.

COCK, J. H. et al. $\mathrm{C}_{3}-\mathrm{C}_{4}$ intermediate photosynthetic characterístics of cassava (Manihot esculenta Crantz) - II. Initial products of ${ }^{14} \mathrm{CO}_{2}$ fixation. Photosynthesis Research, v. 12, p. 237-241, 1987.

EL-SHARKAWY, M. A.; COCK, J. H.; PORTO, M. C. M. Características fotossintéticas da mandioca (Manihot esculenta Crantz). Revista Brasileira de Fisiologia Vegetal, v. 01, n. 02, p. 143-154, 1989.

FERREIRA, D. F. Análises estatísticas por meio do Sisvar para Windows versão 4.0. In: REUNIÃO ANUAL DA REGIÃO BRASILEIRA DA SOCIEDADE INTERNACIONAL DE BIOMETRIA, 45., São Carlos. Anais... São Carlos: UFSCar, 2000. p. 255-258.

GRISI, F. A. et al. Avaliações anatômicas foliares em mudas de café 'Catuaî' e 'Siriema' submetidas ao estresse hídrico. Ciência e Agrotecnologia, v. 32, n. 06, p. 1730-1736, 2008.

JOHANSEN, B. A. Plant microtechnique. New York: McGraw-Hill Book, 1940. 523 p.

HACKE, U. G., SPERRY, J. S. Functional and ecological xylem anatomy. Perspectives in Plant Ecology, Evolution and Sistematics, v. 04, n. 02, p. 97-115, 2001.

LEITE, M. L.; RODRIGUES, J. D.; VIRGENS FILHO, J. S. Efeitos do déficit hídrico sobre a cultura do caupi, cv. EMAPA-821. III. Produção. Revista de Agricultura, v. 75, n. 01, p. 09-20, 2000.
NASSAR, N. M. A. Three brazilian Manihot species with tolerance to stress condictions. Canadian Journal of Plant Science, v. 59, p. 553-555, 1979.

NASSAR, N. M. A. et al. Anatomical alterations due to polyploidy in cassava, Manihot esculenta Crantz. Genetic and Molecular Research, v. 07, n. 02, p. 276-283, 2008.

NASSAR, N. M. A.; ORTIZ, R. Cassava improvement: challenges and impacts. Journal of Agricultural Science, v. 145, p. $163-171,2007$.

OGUCHI, R.; HIKOSAKA, K.; HIROSE, T. Does the photosynthetic light-acclimation need change in leaf anatomy? Plant, Cell and Environment, v. 26, n. 04, p. 505-512, 2003.

OLIVEIRA, J. H. G.; OLIVEIRA, D. M. T. Morfoanatomia e ontogênese do pericarpo de Manihot caerulescens Phol. e Manihot tripartita Müll. Arg. (Eiphorbiaceae). Revista Brasileira de Botânica, v. 32, n. 01, p. 117-119, 2009.

PIMENTEL, C.; PEREZ, A. J. LC. Estabelecimento de parâmetros para avaliação de tolerância à seca em genótipos de feijoeiro. Pesquisa Agropecuária Brasileira, v. 35, n. 01, p. 21-39, 2000.

PEREIRA, F. J. et al. Evolução da anatomia radicular do milho 'Saracura' em ciclos de seleção sucessivos. Pesquisa Agropecuária Brasileira, v. 43, n. 12, p.1649-1656, 2008.

SANTIAGO, E. J. A. et al. Aspectos da anatomia foliar da pimenta-longa (Piper hispidinervium C. DC.) sob diferentes condições de luminosidade. Ciência e Agrotecnologia, v. 25, n. 05, p. 1035-1042, 2001.

SOUZA, G. S. et al. Estrutura foliar e de cloroplastídeos em Mikania laevigata Shultz Bip. ex Baker em diferentes condições de qualidade de luz. Revista Brasileira de Biociências, v. 05. p. 78-80, 2007. Suplemento.

SOUZA, T. C. et al. Morpho-anatomical characterization of root in recurrent selection cycles for flood tolerance of maize (Zea mays L.). Plant, Soil and Environment, v. 55, p. 504-510, 2009.

SOUZA, T. C. et al. Leaf plasticity in sucessive selection cycles of 'Saracura' maize in response to soil flooding. Pesquisa Agropecuária Brasileira, v. 45, n. 01, p. 16-24, 2010.

STRECK, N. A. Stomatal response to water vapor pressure deficit: an unsolved issue. Revista Brasileira de Agrociência, v. 09, n. 04, p. 317-322, 2003.

UENO, O.; AGARIE, S. The intercelullar distribution of glycine decarboxylase in leaves of cassava in relation to photosynthetic mode and leaf anatomy. Japanese Journal of Crop Science, v. 66, n. 02, p. 268-278, 1997.

ZINSOU, V. et al. Leaf waxes of cassava (Manihot esculenta Crantz) in relation to ecozone and resistance to Xanthomonas Blight. Euphytica, v. 149, n. 01/02, p. 189-198, 2006. 